\title{
Incorporating evolutionary processes into population viability models
}

\author{
Jennifer C. Pierson, ${ }^{*}$ I Steven R. Beissinger, † Jason G. Bragg, $\ddagger$ David J. Coates, $\mathbb{\complement}$ \\ J. Gerard B. Oostermeijer, ${ }^{* *}$ Paul Sunnucks, †† Nathan H. Schumaker, $\neq \ddagger$ Meredith V. Trotter, $\$ \mathbb{S}$ \\ and Andrew G. Young*
}

*CSIRO Plant Industry, P.O. Box 1600, Canberra, ACT 2601, Australia

†Department of Environmental Science, Policy and Management, and Museum of Vertebrate Zoology, UC Berkeley, Berkeley, CA 94720, U.S.A.

$\ddagger$ Research School of Biology, The Australian National University, Canberra, ACT 0200, Australia

§Plant Science and Herbarium Program, Department of Parks and Wildlife, Locked Bag 104, Bentley Delivery Centre, Bentley, WA 6983, Australia

**Institute for Biodiversity and Ecosystem Dynamics, University of Amsterdam, Amsterdam, The Netherlands

††School of Biological Sciences, Monash University, VIC 3800, Australia

¥¥Western Ecology Division, Environmental Protection Agency, Corvallis, OR 97333, U.S.A.

§SDepartment of Biology, Stanford University, Stanford, CA 94305, U.S.A.

\begin{abstract}
We examined how ecological and evolutionary (eco-evo) processes in population dynamics could be better integrated into population viability analysis (PVA). Complementary advances in computation and population genomics can be combined into an eco-evo PVA to offer powerful new approaches to understand the influence of evolutionary processes on population persistence. We developed the mechanistic basis of an eco-evo PVA using individual-based models with individual-level genotype tracking and dynamic genotypephenotype mapping to model emergent population-level effects, such as local adaptation and genetic rescue. We then outline bow genomics can allow or improve parameter estimation for PVA models by providing genotypic information at large numbers of loci for neutral and functional genome regions. As climate change and other threatening processes increase in rate and scale, eco-evo PVAs will become essential research tools to evaluate the effects of adaptive potential, evolutionary rescue, and locally adapted traits on persistence.
\end{abstract}

Keywords: adaptation, eco-evolutionary dynamics, extinction risk, genomics, inbreeding, individual-based model, outbreeding, population viability analysis, PVA

Incorporación de Procesos Evolutivos en Modelos de Viabilidad de Población Pierson et al.

Resumen: Examinamos cómo los procesos ecológicos y evolutivos (eco-evo) en la dinámica de poblaciones podrían incorporarse mejor al análisis de viabilidad poblacional (AVP). Los avances complementarios en la computación y la genómica de poblaciones pueden combinarse en un AVP eco-evo para brindar estrategias nuevas y poderosas para entender la influencia de los procesos evolutivos sobre la influencia la persistencia poblacional. Desarrollamos la base mecánica de un AVP eco-evo usando modelos con base en individuos junto con rastreo de genotipo a nivel de individuo y mapeo dinámico de genotipo y fenotipo para modelar los efectos emergentes a nivel poblacional, como la adaptación local y el rescate genético. Después delineamos cómo la genómica puede permitir o mejorar la estimación de parámetros para modelos de AVP eco-evo al proporcionar información genotípica en grandes números de loci para regiones genómicas neutrales y funcionales. Conforme incrementan en tasa y escala el cambio climático y otros procesos amenazantes, los AVP eco-evo se volverán herramientas esenciales de investigación para evaluar los efectos del potencial adaptativo, el rescate evolutivo y las características de persistencia adaptadas localmente.

\Current address: The Fenner School of Environment and Society, The Australian National University, Canberra, ACT O200, Australia. email jennifer.pierson@anu.edu.au

Paper submitted May 25, 2014; revised manuscript accepted September 3, 2014. 
Palabras Clave: adaptación, análisis de viabilidad poblacional, AVP, dinámicas eco-evolutivas, endogamia, exogamia, genómica, modelo con base en individuos, riesgo de extinción

\section{Introduction}

A realistic integration of demography and population genetics, applicable to species in natural environments, is a formidable task that has enticed but largely eluded ecologists and evolutionary biologists.

Lande 1988

Building on the concepts of extinction vortices envisioned by Gilpin and Soulé (1986), Lande (1988) concluded his influential review by emphasizing the need to understand the interaction between demographic and genetic factors on extinction of small populations. More than 25 years later, evolutionary processes are poorly integrated into most models of population viability (i.e., PVA) (Allendorf \& Ryman 2002; Reed et al. 2002; Jamieson \& Allendorf 2012). In a recent search on Web of Science (April 2014), we found that $<15 \%$ (124/841) of studies that included "population viability analysis or PVA" also included "genet*" (where * stands for any characters) and that many of these did not include genetic processes in their PVA (e.g., Blakesley et al. 2010; Meyer et al. 2014; Olsen et al. 2014). Inbreeding depression, the negative fitness consequences of inbreeding, is the primary genetic process incorporated in PVAs, but it has been included in only 60\% of models (Traill et al. 2007). The commonly used stochastic simulation program Vortex (Lacy 1993) models inbreeding depression and change in genetic composition through differential reproductive and survival rates of affected individuals depending upon the genetic load. Most PVAs that included inbreeding depression applied the default Vortex value of 3.14 lethal equivalents (e.g., Aguiar et al. 2010; Eduardo et al. 2012; Zeigler et al. 2013), despite a metaanalysis (O'Grady et al. 2006) reporting an average of $\sim 12$ lethal equivalents (but see Mitchell et al. 2010). Lack of genetic processes in most PVAs reduces their ability to assess how threats affect the evolutionary potential of species to adapt to environmental change.

Recent studies show that evolutionary processes can play decisive roles in extinction risk in a variety of contexts (Palstra \& Ruzzante 2008; Chevin et al. 2010; Ellner et al. 2011). Microevolutionary change occurs through eco-evolutionary feedback between genotypes and phenotypes (Pelletier et al. 2009; Lankau \& Strauss 2011). Shifting environmental conditions can result in microevolutionary changes in wild populations occurring at a much faster pace than previously imagined (Hoffmann \& Sgrò 2011). Evolutionary rescue might ensure population persistence over short time frames by reversing demographic threats caused by environmental stress (Gonzalez et al. 2013). In particular, the capacity of species to adapt to climate change, habitat destruction and fragmentation, introduced diseases, and invasive species will reduce extinction risk for many species.

Two recent advances provide an important opportunity to measure and incorporate the processes of microevolutionary change into PVA models. First, increased computing power and analytical developments support individual-based models (IBMs) of greater complexity (Grimm et al. 2005; Ligtenberg et al. 2010). Second, new genomic technologies and associated bioinformatic data processing are revolutionizing the detection and screening of genome-wide genetic variation and, perhaps more importantly, knowledge of the genomic basis of fitness (Allendorf et al. 2010; Ekblom \& Galindo 2011; Harrisson et al. 2014).

We developed the mechanistic basis of a PVA model that integrates demographic and evolutionary processes, which we call an eco-evo PVA based on similarities with approaches used to understand the dynamics of ecological traits in populations through evolutionary feedback loops (Pelletier et al. 2009; Schoener 2011). We then outline emerging opportunities afforded by genomics to estimate model parameters. Although many parameters are still difficult to estimate for wild populations, now is the time for forward-looking approaches that can direct conservation genomics research toward elucidation of these processes for parameter estimation in tractable systems. We conclude with useful ways eco-evo PVAs can be used in conservation.

\section{Incorporating Eco-Evolutionary Processes in PVAs}

Inbreeding (Vander Wal et al. 2012), outbreeding (Frankham et al. 2011), hybridization (Luquet et al. 2011), selection, and adaptation (Hohenlohe et al. 2010) are central influences on evolutionary processes affecting population persistence (Table 1 ). Early researchers used effective population size $\left(N_{e}\right)$ to assess genetic population viability and evolutionary potential (Frankel \& Soulé 1981; Reed et al. 1988; Nunney \& Elam 1994). Modeling efforts evolved from comparing genetic and demographic estimates of viability based on separate models (Kinnaird \& O'Brien 1991) to incorporating inbreeding depression in a demographic PVA with recessive lethal equivalents (Lindenmayer et al. 1993). Around the same time, Lynch and Lande (1993) developed a theoretical quantitative genetic model of population persistence. Since then, the complexity of both genetic and demographic models has increased, resulting in demographic PVAs that 
Table 1. Incorporating eco-evolutionary processes into PVA.

\begin{tabular}{|c|c|c|c|}
\hline Process & Model parameter & Metric & Metbod of estimation \\
\hline \multirow{5}{*}{ Inbreeding } & inbreeding levels & $F$ & pedigree, estimates from heterozygosity \\
\hline & ploidy & karyotype & chromosome counts \\
\hline & mating system & outcrossing rates, multiple paternity & $\begin{array}{l}\text { parentage analysis, variance in } \\
\text { reproductive success }\end{array}$ \\
\hline & inbreeding depression & $\begin{array}{l}\text { lethal equivalents (LE), deleterious } \\
\text { alleles }\end{array}$ & $\begin{array}{l}\text { breeding experiments, genomic } \\
\text { estimates }\end{array}$ \\
\hline & susceptibility to purging & proportion LE lethal, fitness distributions & $\begin{array}{l}\text { breeding experiments, genomic } \\
\text { estimates }\end{array}$ \\
\hline \multirow{4}{*}{$\begin{array}{l}\text { Selection } \\
\text { and adaptation }\end{array}$} & current genetic fitness & selection coefficients & fitnesses of phenotypes \\
\hline & selective gradients $\left(\mathrm{G}^{*} \mathrm{E}\right)^{a}$ & selection coefficients & $\begin{array}{l}\text { fitnesses of phenotypes in different } \\
\text { environments }\end{array}$ \\
\hline & adaptive potential & evolutionary change (actual or potential) & $\begin{array}{l}\text { evolution experiments, genomic } \\
\text { estimates }\end{array}$ \\
\hline & quantitative traits & narrow-sense $\boldsymbol{b}^{2 b}$ & half-sib or parent-offspring correlations \\
\hline \multirow[t]{2}{*}{ Outbreeding } & outbreeding levels & $F$, introgression & molecular estimates \\
\hline & fitness consequences & fitness distributions & $\begin{array}{l}\text { fitness experiments or measurements, } \\
\text { genomic estimates }\end{array}$ \\
\hline \multirow[t]{2}{*}{ Hybridization } & hybridization levels & admixture score & molecular estimates \\
\hline & fitness consequences & fitness distributions & fitness experiments or measurements \\
\hline
\end{tabular}

${ }^{a}$ The $G^{*} E$ interaction is genotype by environment.

${ }^{b}$ The $b^{2}$ is beritability.

include some genetic processes. For example, Carroll et al. (2014) used wolf pedigrees to incorporate the effect of genetic connectivity on population persistence, and Hostetler et al. (2013) used data on genetic lineage to determine the impact of genetic rescue on population persistence of panthers.

Recent studies have integrated ecological and evolutionary processes to evaluate the effects of environmental perturbations on extinction risk (e.g., Willi \& Hoffmann 2009; Robert 2011; Piou \& Prévost 2012). For example, Dunlop et al. (2007) and Kuparinen and Hutchings (2012) examined different aspects of fisheries-induced evolution on fish populations, whereas Reed et al. (2011) evaluated the evolutionary potential of salmon to adapt to changing climate. Frank and Baret (2013) developed a spatially explicit IBM (SIBM) that incorporated demographic, genetic, and environmental data to examine barriers to upstream migration and stocking of hatchery fish. These examples show how integrating ecological and evolutionary processes in PVAs can address the challenge of population projection under changing environmental conditions, particularly when rapid environmental change may require relatively short-term evolutionary rescue.

We believe integrating evolutionary processes dynamically into PVA models through interactions within and between genetics and demography can best be done using SIBMs, such as HexSim (http://www.hexsim.net), Rangeshifter (Bocedi et al. 2014), and MetaModel (Lacy et al. 2013), which allows Vortex to link with other programs. These SIBMs combine set relationships between genotype, fitness, phenotype, and environment and track individuals (and their genotypes and phenotypes) through time and space. Integral-projection models, which are matrix models that track phenotypes and can examine eco-evolutionary dynamics (Coulson et al. 2010; Rees et al. 2014), do not track the identity of individuals. They also are not capable of addressing spatially complex conservation issues, which limits their applicability to model habitat loss, fragmentation, and spatially explicit movements. For instance, the evolution of dispersal behavior displays eco-evolutionary dynamics that can be directly modeled with SIBMs (Delgado et al. 2014). However, incorporating evolutionary processes into integral-projection models is an emerging area of research (Coulson et al. 2010).

We devised a mechanistic framework for incorporating the major eco-evolutionary processes into PVA (Fig. 1) in which 6 steps are used to model genetic attributes in combination with demographic processes usually incorporated in PVA (Table 2). A seventh and important step-model validation-is not explicitly treated here because it is similar to approaches discussed by others (Ralls et al. 2002; Preuss et al. 2009; Grimm \& Railsback 2012). Each step presents nontrivial tasks of estimating appropriate genetic parameters (Table 1), and we acknowledge that such parameters are available for only few species. But, we anticipate the development of genetic attributes for functional groups of species that will allow generalizations for incorporating genetic data into PVAs. Our hope is that this mechanistic pathway will direct research to improve parameterization of these steps and that genomics will present opportunities for doing so. 


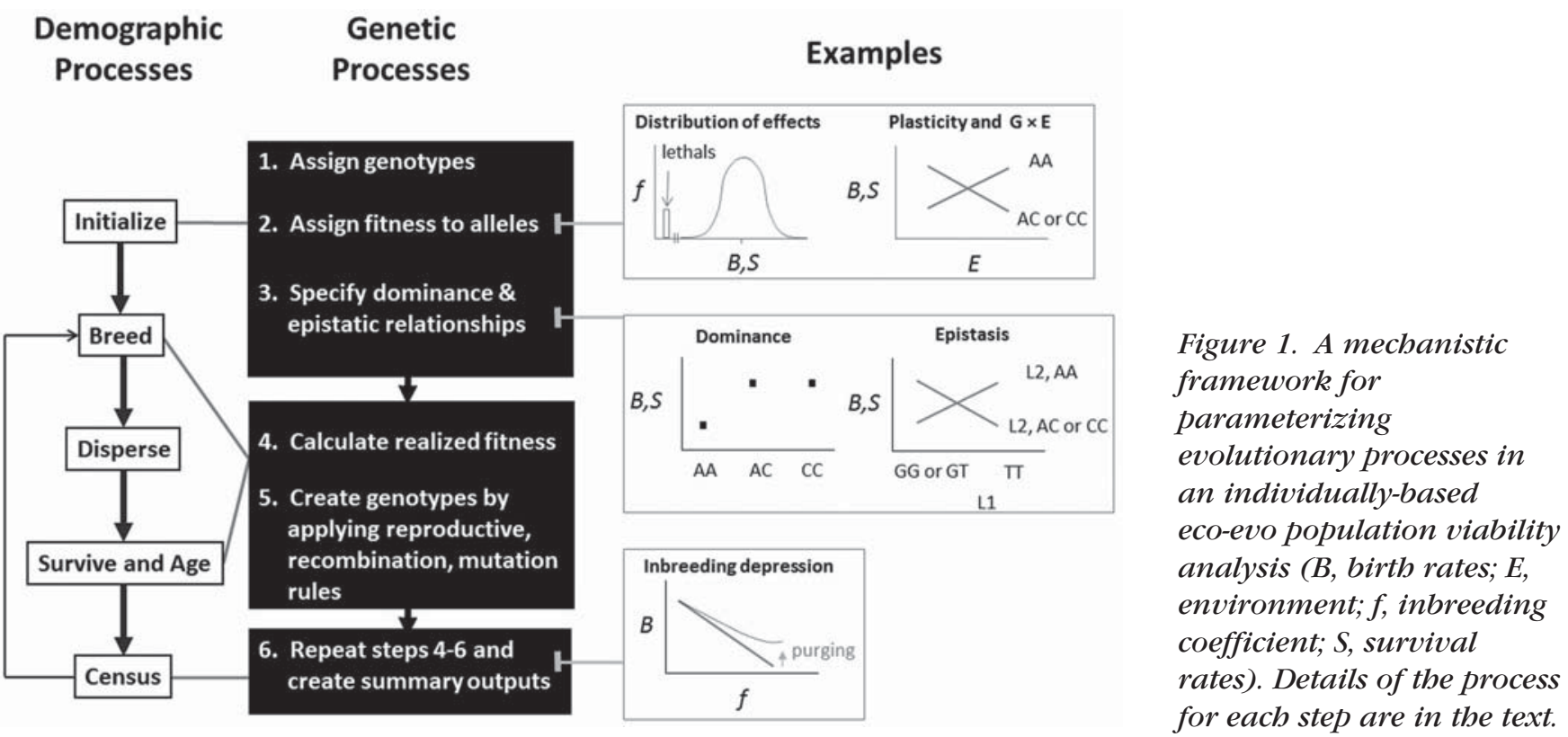

\section{Step 1}

Assign genotypes to individuals based on initial allele frequencies for the portion of the genome simulated. Genotypes assigned to the first generation of individuals in the simulation represent the population's starting point in genotypic space. Ideally, an initial distribution of allele frequencies for each modeled trait locus can be estimated from genetic marker-based data sets to reflect a biologically realistic distribution for a trait of known type and individual genotypes can be assigned based on these distributions. When data are insufficient, a biologically realistic distribution for a known trait type could be used. For example, genes involved in self-incompatibility in plants experience frequency-dependent selection and should have a relatively uniform distribution at equilibrium (Wright 1939). When initial allele frequencies are unavailable, a sensitivity analysis on genetic input parameters can determine the influence of initial parameters on model outcomes.

\section{Step 2}

Assign fitness to alleles or genotypes conditional upon environment. The relative fitness effects of alleles or genotypes should be defined for each locus. This is a substantial task. Recessive lethals are an extreme and relatively simple example of how fitness can be assigned to an allele. More generally, fitness differences can be modeled directly by attributing differential survival or reproduction to alleles according to a frequency distribution (empirically or theoretically derived). This could be done indirectly by assigning phenotypic attributes to alleles (e.g., growth rate) that mechanistically affect fitness (e.g., survival dependent on size) of individuals. Quantitative traits, where many genes may have a small effect, can be modeled by assigning fitness attributes to different combinations of alleles at multiple loci.

Allele- or genotype-specific fitness often varies across environments, which is called genotype-by-environment interactions. For example, local adaptation is typically the result of certain alleles or genotypes having higher fitness in their local environment compared with a distant environment (Anderson et al. 2011). Directional selection can be modeled in relation to environmental variation if it is possible to define either environment-specific allele fitness distributions for patchy environments or functions capturing allelic fitness across continuously varying environments.

\section{Step 3}

Specify dominance and epistatic relationships among alleles. Accurate representation of genotype-phenotype relationships requires defining interactions among alleles. Specifying the dominance relationships among alleles at a locus under selection is essential for modeling realistic shifts in the frequency distribution of alleles due to selective pressures. For example, selection can act much faster on a rare dominant allele compared with a rare recessive allele because recessive alleles must be homozygous to affect an individual's fitness. Dominance relationships are particularly important in the case of inbreeding depression, where the degree and pattern of allelic dominance in relation to fitness determines the likelihood of purging of genetic load (in concert with the distribution of the size of effects of deleterious alleles, population size, and 
Table 2. Data required for the dominant types of demographic models used in population viability analysis: stochastic single-population (SSP), metapopulation (meta), and spatially explicit individual-based model (SIBM).

\begin{tabular}{|c|c|c|c|c|c|}
\hline Data type & Data needs & $S S P$ & $\begin{array}{l}\text { Model type }{ }^{a} \\
\text { Meta }\end{array}$ & SIBM & $G E^{b}$ \\
\hline \multirow[t]{12}{*}{ Demographic } & age or stage structure & $\mathbf{x}$ & $\mathbf{x}$ & $\mathbf{x}$ & $\mathrm{i}$ \\
\hline & age of first breeding & $\mathbf{x}$ & $\mathbf{x}$ & $\mathbf{x}$ & PA \\
\hline & mean fecundity for ages or stages & $\mathbf{x}$ & $\mathrm{P}$ & $\mathrm{P}$ & PA \\
\hline & mean survival/transition for ages or stages & $\mathbf{x}$ & $\mathrm{P}$ & $\mathrm{P}$ & I \\
\hline & number of individuals per age or stage & $\mathbf{x}$ & $\mathrm{P}$ & $\mathrm{P}$ & I \\
\hline & variance in fecundity & $\mathbf{x}$ & $\mathbf{x}$ & $\mathbf{x}$ & PA \\
\hline & variance in survival & $\mathbf{x}$ & $\mathrm{x}$ & $\mathbf{x}$ & I \\
\hline & carrying capacity and density dependence & $\mathbf{x}$ & $\mathrm{P}$ & $\mathrm{P}$ & I \\
\hline & variance in carrying capacity & $\mathbf{x}$ & $\mathbf{x}$ & $\mathbf{x}$ & I \\
\hline & frequency and magnitude of catastrophes & $\mathbf{x}$ & $\mathbf{x}$ & $\mathbf{x}$ & \\
\hline & covariance in demographic rates & $\mathbf{x}$ & $\mathbf{x}$ & $\mathbf{x}$ & \\
\hline & spatial covariance in rates & & $\mathrm{P}$ & $\mathrm{P}$ & \\
\hline \multirow[t]{6}{*}{ Landscape } & patch types & & $\mathbf{x}$ & $\mathbf{x}$ & \\
\hline & distance between patches & & $\mathbf{x}$ & $\mathbf{x}$ & \\
\hline & area of patches & & $\mathbf{x}$ & $\mathbf{x}$ & \\
\hline & location of patches & & & $\mathbf{x}$ & \\
\hline & transitions among patch types & & & $\mathbf{x}$ & \\
\hline & matrix types & & & $\mathbf{x}$ & \\
\hline \multirow[t]{6}{*}{ Dispersal } & number dispersing & & $\mathrm{P}$ & $\mathrm{P}$ & AT \\
\hline & age class and timing of dispersal & & $\mathrm{x}$ & $\mathbf{x}$ & AT \\
\hline & density dependent or independent dispersal & & $\mathbf{x}$ & $\mathbf{x}$ & $\mathrm{AT}, \mathrm{i}$ \\
\hline & dispersal-related mortality & & $\mathbf{x}$ & $\mathbf{x}$ & $\mathrm{AT}, \mathrm{i}$ \\
\hline & number immigrating & & $\mathrm{P}$ & $\mathrm{P}$ & AT \\
\hline & movement rules & & & $\mathbf{x}$ & $\mathrm{AT}, \mathrm{i}$ \\
\hline \multirow[t]{2}{*}{ Genetic } & $\begin{array}{l}\text { number of lethal equivalents } \\
\text { proportion of } \mathrm{IBD}^{b} \text { due to recessive lethals }\end{array}$ & $\mathbf{x}$ & $\mathrm{x}$ & $\mathbf{x}$ & G \\
\hline & $\mathbf{x}$ & $\mathbf{x}$ & $\mathbf{x}$ & G & \\
\hline
\end{tabular}

Adapted from Beissinger and Westphal (1998).

a Abbreviations: $x$, data must be estimated for the population as a whole; $P$, data ideally required to be estimated on a per patch basis

${ }^{b}$ Abbreviations: GE, indicates how genomics and molecular ecology can contribute to parameter estimation; $i$, requires repeated sampling by noninvasive methods; PA, parentage analysis; AT, assignment tests; G, likely possible by genomics if combined with breeding studies for calibration.

${ }^{c}$ Identity by descent.

selection regimes). Heterozygote advantage (overdominance) can be specified by assigning a higher fitness to individuals that are heterozygous at particular loci.

Epistasis results from the interaction of multiple loci on an expressed trait, such as one gene enhancing the expression of another (Phillips 2008). Inbreeding and outbreeding depression can be affected by epistatic interactions among loci, although their role has traditionally been underestimated (Carr \& Dudash 2003). For example, epistatic interactions can arise from adaptation to different local environmental conditions, and disruption after interpopulation crossing can cause outbreeding depression (Allendorf et al. 2013).

\section{Step 4}

Calculate realized fitness of individuals based on steps 2 and 3. The realized fitness of individuals is treated as an emergent property and is calculated by combining the genetic and environmental contributions to fitness from steps 2 and 3. Mates are located and chosen and rules associated with (dis)assortative mating applied. Each individual has a multilocus genotype and fitness based on dominance relationships among alleles, relative fitness of alleles, epistasis among loci, and interactions with environment. The individual's reproductive success, survival, and other metrics of annual fitness emerge from these properties interacting with other stochastic processes (e.g., demographic, environmental) modeled.

\section{Step 5}

Create and assign new multilocus genotypes to offspring by applying reproductive, recombination, and mutation rules.

New offspring from step 4 are created by reproduction, and then segregation, recombination, and mutation rules are applied to assign multilocus genotypes acquired from parents.

\section{Step 6}

Repeat steps 4 and 5 depending upon the model's projection interval and projected time span until the end of simulation and examine model outputs. Population 
viability models often project populations on an annual time step, but they can be constructed with shorter or longer time steps to model the organism of concern. Projections of 50-100 years in the future are common, but longer time spans may be required for eco-evo PVAs aiming to determine equilibrium conditions for evolutionary processes occurring over generations. There is a tradeoff between the desire to produce long-term estimates of population viability and the propagation of errors and increased stochastic variance with each time step (Beissinger \& Westphal 1998). Useful outputs from an eco-evo PVA could include lifetime reproductive success, population size (census and effective), genotypes (for genetic analysis with other software such as Arlequin), levels of heterozygosity for neutral and adaptive loci, allelic richness $(A)$, inbreeding coefficients $(F)$, and genetic variance $(V)$ among others.

Evolutionary genetic processes such as genetic drift, gene flow, inbreeding depression, outbreeding depression, and adaptation are emergent properties of the IBM modeling framework (Fig. 1). These processes emerge from the mating of individuals and their survival, depending on their genotypes, the environment they inhabit, dominance, and epistasis. For example, adaptation emerges when individuals have an allele that results in differential fitness based on a phenotype or population origin. Inbreeding depression emerges when alleles designated as recessive and deleterious are homozygous in individuals and reduce fitness. Outbreeding depression emerges when an individual has an allele adapted to a different location that produces reduced fitness in its current location. These examples are just a few ways eco-evolutionary processes emerge from SIBMs, which provide power to flexibly and mechanistically project populations in space and time.

\section{Estimating Eco-Evolutionary Parameters for PVAs}

A major limitation to incorporating evolutionary processes into PVA models has been the difficulty of estimating model input parameters, especially for nonmodel species. Recent reviews of conservation genetics have outlined potential ways genomics can improve understanding of ecological and evolutionary population processes in nonmodel species (e.g., Allendorf et al. 2010; Ekblom \& Galindo 2011; Harrisson et al. 2014). Our intent is not to further review how genomics may create new possibilities, but to highlight a few important areas of research that show promise for estimating key evolutionary processes and their effects on population viability (Tables $1 \& 2$ ). Challenges, such as a lack of reference genome for nonmodel species or limited understanding of how past population history influences parameters, may need to be overcome for many of these methods. Our goal is to stimulate discussion around promising areas of research in conservation genomics to understand and attain estimates of these parameters, concentrating on 3 areas of key concern to conservation geneticists.

\section{Inbreeding and Inbreeding Depression}

Inbreeding depression arises when an inbred mating increases homozygosity and causes the expression of harmful recessive or partially recessive alleles that otherwise would not have affected the phenotype. Inbreeding depression leads to the loss of favorable genetic combinations that may occur within and among loci. Genomics may improve estimates of the genetic architecture of inbreeding depression and uncover the kinds of genes that cause it. For example, genome-wide screening of Pacific oysters (Crassostrea gigas) revealed 14-15 viability loci within 2 families that accounted for $96 \%$ of mortality. Loci were generally recessive or partially recessive, and there was no evidence of epistasis (Plough \& Hedgecock 2011). Compilations of such studies should lead to useful generalities for application in cases where no data are available.

Parameterizing inbreeding depression requires estimates of inbreeding. A promising new estimator of individual inbreeding coefficient $\left(F_{\mathrm{ROH}}\right)$ uses runs of homozygosity $(\mathrm{ROH}$, regions of the genome that are homozygous due to shared ancestry). This measure reflects shared ancestry over considerable periods, retains variation even in large populations, and can be examined for different genome regions (Keller et al. 2011). These methods are being extended to examine the relationship between $F_{\mathrm{ROH}}$ and quantitative traits as a means to predict inbreeding depression (McQuillan et al. 2012). Limitations of these approaches, including the influence of different demographic histories and selection, are currently being tested in humans and domestic animals (Silió et al. 2013; Power et al. 2014).

Complementary approaches to understand the fitness consequences of individual genetic variation employ estimators of genome-wide heterozygosity keyed to fitness attributes (HFCs, heterozygosity-fitness correlations). Candidate suitable genomic approaches include restriction site-associated DNA (RAD), which does not require a reference genome. This method was recently validated on oldfield mice (Peromyscus polionotus) with a known pedigree and then successfully applied to a natural population of harbor seals (Pboca vitulina) (Hoffmann et al. 2014). However, there is still much to be done to understand the relationship between HFCs and inbreeding depression (Kardos et al. 2014).

\section{Evolutionary Potential, Selection, and Adaptation}

Evolutionary potential, the spatial distribution of functional or adaptive genetic diversity, will be a decisive factor in determining the persistence of many organisms 
under environmental change (Sgrò et al. 2011). Numerous studies have tested for genomic signals of selection in model and nonmodel organisms (e.g., Nielsen et al. 2009; Zhao et al. 2012; Grossman et al. 2013). Discovering markers under selection and the genomic architecture of adaptation is complex due to the interacting effects of population history, polygenic control of phenotypes with weak selection, different modes of selection, and the difficulty of identifying an appropriate null model (Coop et al. 2009).

Quantitative genetic approaches can be used to estimate additive genetic variation (correlated with evolutionary potential) for fitness traits. However, this method has been used rarely for wild populations because it is time-consuming, requires information on relatedness among individuals, and needs large sample sizes to achieve adequate precision (but see DiBattista et al. 2009). Furthermore, alleles that are beneficial in one environment are often deleterious in another. More commonly, neutral genetic variation is used to infer adaptive genetic variation, even though it may be a poor surrogate when applied to few markers (Reed \& Frankham 2001).

Genome-wide association studies (GWAS) are a common approach when seeking correlations between patterns of genetic variation and phenotypic traits. These studies have identified loci associated with key traits, such as migratory behavior (a quantitative trait) in rainbow and steelhead trout (Oncorbynchus mykiss; Hecht et al. 2012), and climate-adapted phenotypes, such as variance in bud-set and cold-hardiness in Sitka spruce (Picea sitchensis) (Holliday et al. 2010). To relate genomic variation to future evolution, the recent measure environmental relevance, which assesses how much variation is explained by environmental variables after accounting for population structure, is worthy of evaluation (Lee \& Mitchell-Olds 2012).

Although genomics is adding our knowledge of the mechanisms of adaptation (Grossman et al. 2013), converting new insights into parameter estimates for PVA is likely to be incremental. We advocate cyclic synthesis of information, hypothesis formation and empirical tests by genomic monitoring of natural populations, and experimental evolution (Kawecki et al. 2012).

\section{Outbreeding Depression and Hybridization}

Outbreeding depression is a consequence of gene flow (outbreeding) between different genetically diverged populations within species. It is associated with fixed chromosomal differences, long divergence times, coadapted gene complexes, and substantial differences in environmental adaptation (Frankham et al. 2011).

Chromosomal rearrangements are detectable by pairend genome sequencing, and genomics approaches are particularly powerful when combined with cytogenetics (Allendorf et al. 2010). New approaches based on shared haplotype lengths can estimate the timing and amount of admixture, change in population size, and divergence times over a range of time scales (Harris \& Nielsen 2013). Genomics also affords the potential to identify loci that mediate adaptation to local conditions (Steiner et al. 2013), where the risk of outbreeding depression would be elevated (Frankham et al. 2011).

Hybridization leading to taxonomic swamping may be a concern when different species come into contact through introductions and habitat disturbance. Genomic approaches can improve detection of hybridization if many loci are used and the linkage relationships of these loci are known (Hohenlohe et al. 2011).

\section{Engaging Eco-Evo PVAs in Conservation Decisions}

Eco-evo PVAs are likely to become important tools for conservation decision making in our rapidly changing world. The inclusion of evolutionary processes in population projections, such as adaptation and evolutionary rescue (Franks \& Hoffmann 2012), will be necessary to adequately model population dynamics and may provide more realistic and optimistic outlooks for species than PVAs that model the effects of global warming and other threats in the absence of eco-evolutionary change. As flexibility in SIBM software increases and the genomics revolution unrolls, eco-evo PVAs could become a more realistic goal of recovery programs for threatened and conservation-dependent species.

The reality of limited funding for conservation requires consideration of when adding genetic processes to PVAs is cost-effective. Generally, populations with high susceptibility to genetic impacts on viability have a small current $N_{e}$, have recently declined from a historically large population size, are fragmented with low gene flow, are metapopulations with high rates of population extinction, or have self-incompatibility systems, a sex locus, or strong inbreeding avoidance systems. Such species could be given high priority for the development of ecoevo PVAs. Alternatively, species with comparatively low susceptibility to genetic impacts on population viability would have at least some of the following characteristics: history of small $N_{\mathrm{e}}$, large current $N_{e}$, strictly asexual reproduction, high rates of selfing, haplodiploid, or polyploidy.

Eco-evo PVAs still embody the shortcomings and caveats of current PVA models (Beissinger \& Westphal 1998; Akçakaya 2000; Morris \& Doak 2002). The increased model complexity and number of parameters in an eco-evo PVA will be associated with increased uncertainty in model outputs, even if compensated by greater realism. Thus, caution is needed in the interpretation of model results, especially in the early phases of evolutionary parameter estimation, because uncertainty around estimates will likely be unknown. We recommend the focus remain on PVAs as decision-support tools for 
evaluating relative differences among scenarios such as competing management options or the roles of different processes, for sensitivity analyses to compare the relative importance of data inputs and processes, and for informing research agendas (Reed et al. 2002).

\section{Acknowledgments}

This work was supported by funding from the Australian Centre for Ecological Analysis and Synthesis (ACEAS). The U.S. Environmental Protection Agency (EPA) funded N.H.S. and approved this paper for publication. Approval does not imply the content reflects the views of EPA. The manuscript benefitted from comments by V. Grimm, P. Palsbøll, and 2 anonymous reviewers.

\section{Literature Cited}

Aguiar LMS, Brito D, Machado RB. 2010. Do current vampire bat (Desmodus rotundus) population control practices pose a threat to Dekeyser's nectar bat's (Lonchophylla dekeyseri) long-term persistence in the Cerrado? Acta Chiropterologica 12:275-282.

Akçakaya HR 2000. Population viability analyses withdemographically and spatially structured models. Ecological Bulletins 48:23-38.

Allendorf FW, Ryman N. 2002. The role of genetics in population viability analysis. Pages 50-85 in Beissinger SR, McCullough DR, editors. Population viability analysis. University of Chicago Press, Chicago, Illinois.

Allendorf FW, Hohenlohe PA, Luikart G. 2010. Genomics and the future of conservation genetics. Nature Reviews Genetics 11:697-709.

Allendorf FW, Luikart G, Aitken S. 2013. Conservation and the genetics of populations. 2nd edition. Wiley-Blackwell, Oxford, United Kingdom.

Anderson JT, Willis JH, Mitchell-Olds T. 2011. Evolutionary genetics of plant adaptation. Trends in Genetics 27:258-266.

Beissinger SR, Westphal MI. 1998. On the use of demographic models of population viability in endangered species management. The Journal of Wildlife Management 62:821-841.

Blakesley JA, et al. 2010. Population dynamics of spotted owls in the Sierra Nevada, California. Wildlife Monographs 174:1-36.

Bocedi G, Palmer SCF, Pe'er G, Heikkinen RK, Matsinos YG, Watts K, Travis JMJ. 2014. Rangeshifter: a platform for modelling spatial eco-evolutionary dynamics and species' responses to environmental changes. Methods in Ecology and Evolution 5:388-396

Carr DE, Dudash MR. 2003. Recent approaches into the genetic basis of inbreeding depression in plants. Philosophical Transactions of the Royal Society of London. Series B: Biological Sciences 358:10711084

Carroll CRJ, Fredrickson RJ, Lacy RC. 2014. Developing metapopulation connectivity criteria from genetic and habitat data to recover the endangered Mexican wolf. Conservation Biology 28:76-86.

Chevin LM, Lande R, Mace GM. 2010. Adaptation, plasticity, and extinction in a changing environment: towards a predictive theory. PLOS Biology (e1000357) DOI: 10.1371/journal.pbio. 1000357.

Coop G, Pickrell JK, Novembre J, Kudaravalli S, Li J, Absher D, Myers RM, Cavalli-Sforza LL, Feldman MW, Pritchard JK. 2009. The role of geography in human adaptation. PLOS Genetics (e1000500) DOI: 10.1371/journal.pgen.1000500.

Coulson T, Tuljapurkar S, Childs DZ. 2010. Using evolutionary demography to link life history theory, quantitative genetics and population ecology. Journal of Animal Ecology 79:1226-1240.
Delgado MM, Barton KA, Bonte D, Travis JMJ. 2014. Prospecting and dispersal: their eco-evolutionary dynamics and implications for population patterns. Proceedings of the Royal Society B 281:20132851.

DiBattista JD, Feldheim KA, Garant D, Gruber SH, Hendry AP. 2009. Evolutionary potential of a large marine vertebrate: quantitative genetic parameters in a wild population. Evolution 63:1051-1067.

Dunlop ES, Shuter BJ, Dieckmann U. 2007. Demographic and evolutionary consequences of selective mortality. Transactions of the American Fisheries Society 136:749-765.

Eduardo AA, Nunes AV, Brito D. 2012. Do the protected areas network of the state of Minas Gerais maintain viable populations of the lowland tapir (Tapirus terrestris)? Natureza \& Conservação 10:27-33.

Ekblom R, Galindo J. 2011. Applications of next generation sequencing in molecular ecology of non-model organisms. Heredity 107: $1-15$.

Ellner SP, Geber MA, Hairston NG. 2011. Does rapid evolution matter? Measuring the rate of contemporary evolution and its impacts on ecological dynamics. Ecology Letters 14:603-614.

Frank BM, Baret PV. 2013. Simulating brown trout demogenetics in a river/nursery brook system: the individual-based model DemGenTrout. Ecological Modelling 248:184-202.

Frankel OH, Soulé ME. 1981. Conservation and evolution. Cambridge University Press, Cambridge, United Kingdom.

Frankham R, Ballou JD, Eldridge MD, Lacy RC, Ralls K, Dudash MR, Fenster CB. 2011. Predicting the probability of outbreeding depression. Conservation Biology 25:465-475.

Franks SJ, Hoffmann AA. 2012. Genetics of climate change adaptation. Annual Review of Genetics 46:185-208.

Gilpin ME, Soulé ME. 1986. Conservation biology: the science of scarcity and diversity. Sinauer Associates, Sunderland, Massachusetts.

Gonzalez A, Ronce O, Ferriere R, Hochberg ME. 2013. Evolutionary rescue: an emerging focus at the intersection between ecology and evolution. Phil Trans R Soc B 368:20120404.

Grimm V, Revilla E, Berger U, Jeltsch F, Mooij WM, Railsback SF, Thulke HH, Weiner J, Wiegand T, DeAngelis DL. 2005. Pattern-oriented modeling of agent-based complex systems: lessons from ecology. Science 310:987-991.

Grimm V, Railsback SF. 2012. Pattern-oriented modelling: a "multiscope" for predictive systems ecology. Philosophical Transactions Royal Society London B 367:298-310.

Grossman SR, et al. 2013. Identifying recent adaptations in large-scale genomic data. Cell 152:703-713.

Harris K, Nielsen R. 2013. Inferring demographic history from a spectrum of shared haplotype lengths. PLOS Genetics (e1003521) DOI: 10.1371/journal.pgen.1003521.

Harrisson KA, Pavlova A, Telonis-Scott M, Sunnucks P. 2014. Using genomics to characterize evolutionary potential for conservation of wild populations. Evolutionary Applications 7:1008-1025. DOI:10.1111/eva.12149.

Hecht BC, Campbell N, Holecek DE, Narum SR. 2012. Genome-wide association reveals genetic basis for the propensity to migrate in wild populations of rainbow and steelhead trout. Molecular Ecology 22:3061-3076.

Hoffmann AA, Sgró CM. 2011. Climate change and evolutionary adaptation. Nature 470:479-485.

Hohenlohe PA, Bassham S, Etter PD, Stiffler N, Johnson EA, Cresko WA. 2010. Population genomics of parallel adaptation in threespine stickleback using sequenced RAD tags. PLOS Genetics (e1000862) DOI: 10.1371 /journal.pgen.1000862.

Hohenlohe PA, Amish SJ, Catchen JM, Allendorf FW, Luikart G. 2011. Next-generation RAD sequencing identifies thousands of SNPs for assessing hybridization between rainbow and westslope cutthroat trout. Molecular Ecology Resources 11:117-122.

Holliday JA, Ritland K, Aitken SN. 2010. Widespread, ecologically relevant genetic markers developed from association mapping of climate-related traits in Sitka spruce (Picea sitchensis). New Phytologist 188:501-514. 
Hostetler JA, Onorato DP, Jansen D, Oli MK. 2013. A cat's tale: the impact of genetic restoration on Florida panther population dynamics and persistence. Journal of Animal Ecology 82:608-620. DOI: 10.1111/1365-2656.12033.

Jamison IG, Allendorf FW. 2012. How does the 50/500 rule apply to MVPs? Trends in Ecology and Evolution 27:578-584.

Kardos M, Allendorf FW, Luikart G. 2014. Evaluating the role of inbreeding depression in heterozygosity-fitness correlations: How useful are tests for identity disequilibrium? Molecular Ecology Resources 14:519-530.

Kawecki TJ, Lenski RE, Ebert D, Hollis B, Olivieri I, Whitlock MC. 2012. Experimental evolution. Trends in Ecology \& Evolution 27:547-560.

Keller MC, Visscher PM, Goddard ME. 2011. Quantification of inbreeding due to distant ancestors and its detection using dense single nucleotide polymorphism data. Genetics 189:237-249.

Kinnaird MF, O'Brien TG. 1991. Viable populations for an endangered forest primate, the Tana River Crested Mangabey (Cercocebus galeritus galeritus). Conservation Biology 5:203-213.

Kuparinen A, Hutchings JA. 2012. Consequences of fisheries-induced evolution for population productivity and recovery potential. Proceedings of the Royal Society B: Biological Sciences 279:2571-2579.

Lacy RC. 1993. VORTEX: a computer simulation model for population viability analysis. Wildlife Research 20:45-65.

Lacy RC, Miller PS, Nyhus PJ, Pollak JP, Raboy BE, Zeigler S. 2013. Metamodels for transdisciplinary analysis of population dynamics. PLOS ONE (e84211) DOI: 10.1371/journal.pone.0084211.

Lande R. 1988. Genetics and demography in biological conservation. Science 241:1455-1460.

Lankau RA, Strauss SY. 2011. Newly rare or newly common: evolutionary feedbacks through changes in population density and relative species abundance, and their management implications. Evolutionary Applications 4:338-353.

Lee CR, Mitchell-Olds T. 2012. Environmental adaptation contributes to gene polymorphism across the Arabidopsis thaliana genome. Molecular Biology and Evolution 29:3721-3728.

Ligtenberg A, van Lammeren RJ, Bregt AK, Beulens AJ. 2010. Validation of an agent-based model for spatial planning: A role-playing approach. Computers, Environment and Urban Systems 34:424434

Lindenmayer DB, Lacy RC, Thomas VC, Clark TW. 1993. Predictions of the impacts of changes in population size and environmental variability on Leadbeater's possum, Gymnobelideus leadbeateri McCoy (Marsupialia: Petauridae) using Population Viability analysis: an application of the computer program Vortex. Wildlife Research 20:67-85

Luquet E, Vorburger C, Hervant F, Joly P, Kaufmann B, Schmeller DS, Léna JP, Grolet O, Konecny L, Plénet S. 2011. Invasiveness of an introduced species: the role of hybridization and ecological constraints. Biological Invasions 13:1901-1915.

Lynch M, Lande R. 1993. Evolution and extinction in response to environmental change. Pages 234-250 in Kareiva PM, Kingsolver JG, and RB Huey, editors. Biotic interactions and global change. Sinauer Associates, Sunderland, Massachusetts.

McQuillan R, Eklund N, Pirastu N, Kuningas M, McEvoy BP, Esko T, Corre T, Davies G, Kaakinen M, Lyytikäinen LP. 2012. Evidence of inbreeding depression on human height. PLOS Genetics (e1002655) DOI: 10.1371 /journal.pgen.1002655

Meyer KA, Garton EO, Schill DJ. 2014. Bull trout trends in abundance and probabilities of persistence in Idaho. North American Journal of Fisheries Management 34:202-214.

Mitchell NJ, Allendorf FW, Keall SN, Daugherty CH, Nelson NJ. 2010. Demographic effects of temperature-dependent sex determination: Will tuatara survive global warming? Global Change Biology 16:6072 .

Morris WF, Doak DK. 2002. Quantitative conservation biology. Sinauer Associates Inc., Sunderland, Massachusetts.
Nielsen EE, Hemmer-Hansen J, Larsen PF, Bekkevold D. 2009. Population genomics of marine fishes: identifying adaptive variation in space and time. Molecular Ecology 18:3128-3150.

Nunney L, Elam DR. 1994. Estimating the effective population size of conserved populations. Conservation Biology 8: 175-184.

O'Grady JJ, Brook BW, Ballou JD, Tonkyn DW, Frankham R. 2006. Realistic levels of inbreeding depression strongly affect extinction risk in wild populations. Biological Conservation 133:42-51

Olsen MT, Andersen LW, Dietz R, Teilmann J, Härkönen T, Siegismund HR. 2014. Intergrating genetic data and population viability analyses for the identification of harbour seal (Phoca vitulina) populations and management units. Molecular Ecology 23:815-831.

Palstra FP, Ruzzante DE. 2008. Genetic estimates of contemporary effective population size: What can they tell us about the importance of genetic stochasticity for wild population persistence? Molecular Ecology 17:3428-3447.

Pelletier F, Garant D, Hendry AP. 2009. Eco-evolutionary dynamics. Philosophical Transactions of the Royal Society B 364:14831489.

Phillips PC. 2008. Epistasis-the essential role of gene interactions in the structure and evolution of genetic systems. Nature Reviews Genetics 9:855-867.

Piou C, Prévost E. 2012. A demo-genetic individual-based model for Atlantic salmon populations: model structure, parameterization and sensitivity. Ecological Modelling 231:37-52.

Plough LV, Hedgecock D. 2011. Quantitative trait locus analysis of stagespecific inbreeding depression in the Pacific oyster Crassostrea gigas. Genetics 189:1473-1486.

Power RA, et al. 2014. A recessive genetic model and runs of homozygosity in major depressive disorder. American Journal of Medical Genetics, Part B: Neuropyschiatric Genetics 165:157-166.

Preuss TP, Hammers-Wirtz M, Hommen U, Rubach MN, Ratte HT. 2009. Development and validation of an individual based Daphnia magna population model: the influence of crowding on population dynamics. Ecological Modelling 220:310-329.

Ralls K, Beissinger SR, Cochrane JF. 2002. Guidelines for using population viability analysis in endangered species management. Pages 521-550 in Beissinger SR, McCullough DR, editors. Population viability analysis. University of Chicago Press, Chicago, Illinois.

Reed JM, Doerr PD, Walters JR. 1988. Minimum viable population size of the red-cockaded woodpecker. The Journal of Wildlife Management 52:385-391.

Reed DH, Frankham R. 2001. How closely correlated are molecular and quantitative measures of genetic variation? a meta-analysis. Evolution 55:1095-1103

Reed JM, Mills LS, Dunning JB, Menges ES, McKelvey KS, Frye R, Beissinger SR, Anstett MC, Miller P. 2002. Emerging issues in population viability analysis. Conservation Biology 16:7-19.

Reed TE, Schindler DE, Hague MJ, Patterson DA, Meir E, Waples RS, Hinch SG. 2011. Time to evolve? Potential evolutionary responses of Fraser River sockeye salmon to climate change and effects on persistence. PLOS ONE (e20380) DOI:10.1371/journal.pone.0020380.

Rees M, Childs DZ, Ellner SP. 2014. Building integral projection models: a user's guide. Journal of Animal Ecology 83:528-545.

Robert A. 2011. Find the weakest link: a comparison between demographic, genetic and demo-genetic metapopulation extinction times. BMC Evolutionary Biology 11:260-269.

Schoener TW. 2011. The newest synthesis: understanding the interplay of evolutionary and ecological dynamics. Science 331:426-429.

Sgrò CM, Lowe AJ, Hoffmann AA. 2011. Building evolutionary resilience for conserving biodiversity under climate change. Evolutionary Applications 4:326-337.

Silió L, Rodríguez MC, Fernández A, Barragán C, Benítez R, Óvilo C, Fernández AI. 2013. Measuring inbreeding and inbreeding 
depression on pig growth from pedigree or SNP-derived metrics. Journal of Animal Breeding and Genetics 130:349-360.

Steiner CC, Putnam AS, Hoeck PEA, Ryder OA. 2013. Conservation genomics of threatened animal species. Annual Review of Animal Biosciences 1:261-281.

Traill LW, Bradshaw CJA, Brook BW. 2007. Minimum viable population size: a meta-analysis of 30 years of published estimates. Biological Conservation 139: 159-166.

Vander Wal, E, Garant D, Festa-Bianchet M, Pelletier F. 2012. Evolutionary rescue in vertebrates: evidence, applications, and uncertainty. Philosophical Transactions of the Royal Society B 368: 20120090
Willi Y, Hoffmann AA. 2009. Demographic factors and genetic variation influence population persistence under environmental change. Journal of Evolutionary Biology 22:124-133.

Wright S. 1939. The distribution of self-sterility alleles in populations Genetics 24:538-552.

Zhao S, et al. 2012. Whole-genome sequencing of giant pandas provides insights into demographic history and local adaptation. Nature Genetics 45:67-71.

Zeigler SL, De Vleeschouwer KM, Raboy BE. 2013. Assessing extinction risk in small meta-populations of golden-headed lion tamarins (Leontopithecus chrysomelas) in Bahia State, Brazil. Biotropica 45:528535. 